\title{
Integrated Research of Geotechnical Engineering Investigation and Design Based on GIS Technology
}

\author{
Qing $\operatorname{Han}^{1}$ \\ Xijing University, Xi'an, 710123, China \\ E-mail: 1042529789@qq.com
}

\author{
Jun $\operatorname{Sun}^{2}$ \\ Xijing University, Xi'an, 710123, China \\ E-mail: 461278500@qq.com
}

\begin{abstract}
This paper is based on the author's years of experience in geotechnical engineering investigation. This paper discusses the current situation and existing problems, and analyzes the system of the integration of geotechnical investigation from the field practice, and the role of GIS in the system construction is given based on the integration system of geotechnical engineering investigation. The full text is the author's theory on the basis of long-term work, believing that the relevant work of the peer has important value on reference and imitate.
\end{abstract}

Keywords-Integration of Geotechnical Engineering; Investigation Construction; the Integrative of Geotechnology Survey and Design; GIS

\section{INTRODUCTION}

Geotechnical engineering investigation is a prerequisite for engineering design. General geo-technical engineering information including topography, land Layer interface, fault, underground water level, thickness of weathering layer and various geophysical and geochemical prospecting data are obtained from field measurement. Although in engineering design they played an integral role, after project finished it was put "on the shelf", in their general and rarely used. Even if the "one day" is used, the information is only a few discrete data, and it is difficult to use them to analyze the distribution of engineering geological parameters directly in the field. Besides the traditional geotechnical engineering data analysis and interpretation are generally confined in two-dimensional and static. This expression describes the spatial structure fluctuation changes, often cannot fully reveal the law of spatial variation [1]. It is difficult to make people, complete and accurate geographical solution and feel the physical and mechanical properties of soil directly, so it cannot meet the requirements of the project. How to use these parameters to infer the distribution of them in the region, and how to use these parameters to predict the geotechnical engineering properties of a certain point in the site is an old and interesting problem in geotechnical engineering. Today, with the development of computer, especially the development of DataBase theory, the perfection of computer graphics processing technology, the above problems are becoming more and more novelty. Along with the development of computer technology, it has been fully integrated with geotechnical engineering, geotechnical engineering, geotechnical engineering database management, geotechnical engineering characteristics analysis, geotechnical engineering. The integrated system of the process of geological interpretation, spatial analysis and prediction, geological statistics and graphics visualization, and then developed into a new system of geotechnical engineering investigation, which has become a modern and informational. Theory, experiment and computer technology have become the three major pillars of the development of the subject. The application of subject computer technology in the discipline has bred a new revolution. This revolution will spread to the field of geotechnical engineering investigation [2].

\section{CURRENT SITUATION AND EXISTING PROBLEMS OF GEOTECHNICAL ENGINEERING INVESTIGATION IN CHINA}

Since liberation, China's geotechnical engineering investigation and design work has made considerable progress, especially in the application of computer technology and modern technology, so that the geotechnical engineering investigation, design work is rapid development, the main performance in the follow:

(1) There is great progress and improvement in the application of geotechnical engineering reconnaissance in equipment and advanced technology, especially in 1990s [3];

(2) With the development and integration of RS, GIS, GPS (3S Technology), the integration of geotechnical engineering investigation and design has been prompted to enter into the integrated industrial system of survey and design, which made the database as the core. While watching the development of the above, it should also be noted that although the computer aided design (CAD) has been widely used in geotechnical engineering survey design, the function is increasingly perfect. However, due to various reasons, there are still many problems to be improved, and we need to overcome the existing problems, so that the integration of geotechnical engineering investigation in China has made considerable progress [4]. The main problems are as follows:

1) Geological prospecting data.

2) The professional design Inter - counting system.

3) Digital map and digital design system cut-through are not enough.

4) Design software is not perfect.

5) Software system closed

6) Low survey information

7) System integrated ability 
8) The existing geotechnical engineering investigation and design system has no space analysis ability.

9) The results of the study keep away from the actual use

\section{SOLUTION METHOD}

From the above it can be seen that at present, the most important problem in geotechnical engineering is to survey and design the separation and the design software function is not perfect. To solve the current problems, it is urgent to establish a system of integration. The main characteristics of the integrated operation are to survey and design the use of computer operations [5]. As depicted in Figure 1The investigation stage is the design phase, the upper and the working procedure is the next working procedure, and the special type of work provides the interface data to make the data transfer smoothly, to achieve data sharing. In this way, the operating speed more quickly, shorten the design cycle, the file data, consistent, clean, high quality, so as to improve the geotechnical engineering survey design of the efficiency, save manpower, improve the economic benefits

In order to realize the geotechnical engineering survey and design of the book, we should realize digital geotechnical engineering design process. Advanced geographic information system technology (GIS), spatial data management technology, geotechnical engineering modeling technology, computer graphics technology, geological statistics and the theory of the airport, this technology and theory should be the basis for the realization of geotechnical engineering survey and design [6].

The integrated system of geotechnical engineering investigation and design is the integration of subject computer technology system engineering, which is a multidiscipline and multi subject. Integration is innovation, so the geotechnical engineering. Investigation and design of integrated construction is a long-term and arduous task. To solve the current problems, we need to establish a unified framework and collaborative work environment, design and implement the system. On the other hand, we should make full use of a large number of mature technologies and seek new or needed advanced technology, such as virtual reality technology, expert system, data mining and knowledge discovery technology. Although these technologies emerged only a few decades ago, and even more than ten years, a few years, they have been many great progresses in the application of geotechnical engineering investigation.

\section{INTEGRATION OF GEOTECHNICAL ENGINEERING INVESTIGATION}

\section{A. Integrated Definition of Geotechnical Engineering Investigation}

By definition, integration is a combination of a number of elements or elements of a variety of diverse elements or units that are integrated into a more integrated or coordinated. As the integration creates a more complete or coordinated overall, it was considered as a great value process [7] as is depicted in Figure 2

In geotechnical engineering investigation and design, integration is usually considered as a way to combine different disciplines, and this way can help to establish (or create) a new analysis process.

In reality, integration is a very difficult concept to be defined. Survey and design contains many basic disciplines, so there are many problems in practice. Based on this situation, the integration has the following understanding [8].

(1) Vertical and horizontal integration. A basic distinction can be made according to the horizontal integration of the vertical integration of survey and design disciplines and the cross integration of multi disciplines. One example of vertical integration is the different geophysical exploration techniques to work on the same platform with different geophysical methods of interpretation. Interpretation of special engineering site conditions and horizontal integration refers to the integration of different disciplines. Horizontal integration is more complex, and the main difficulty is that the interoperability is relatively small, and in the vast majority of cases, different professional and technical personnel more focused on their own special research.

(2) Loosely and closely integrated. Loose and close integration mainly refers to the degree of interoperability between different applications. Loose and close integration can be determined the meaning and work process in general. When a structural geologist and a civil engineer discuss the fault location in their research work, this is called a loose integration. When a few structural geologists work together in order to determine location of the fault with their own tools, this integration is completed. [9]

(3) The integrated system of geotechnical engineering investigation is the application of modern surveying and mapping technology, database technology, computer technology, network communication technology and CAD technology, through the computer and software, to integration a project's all information (surveying, design, schedule, plan and change data) orderly, establish a comprehensive computer aided information flow, survey the design technology from manual mode to modern CAD technology transformation, data acquisition system, survey data processing digital, hardware system network, graphic processing automation, gradually formed and to establish a more professional, more types production and in high efficiency, flexibility, intelligence engineering survey and design system. The integrated system of geotechnical engineering investigation and design can include four parts, namely data acquisition system, survey information processing system, geotechnical engineering investigation and design DataBase management system, computer document management system, and geotechnical engineering investigation system.

\section{B. The Composition of the Integrated System of Geotechnical Engineering Investigation}

The geological information system (GIS) includes a series of technology database, computer graphics, geology, geological modeling, WORD and AutoCAD automation and so on. They take the rock soil engineering survey, design specifications as a basis for mutual connection to form a system engineering [8], as shown in Figure 1.

This integration system will be more closely linked to many disciplines, which changed the past that the subject work independently and there is no way to communicate 
with each other. It prompted mutual communication and feedback among various subjects. On the above, we should understand that we must realize the integration of geotechnical engineering investigation, before realize the geotechnical engineering investigation. Geotechnical engineering reconnaissance digitization is a prerequisite for the realization of the integration. The main content of this paper is related to the work of geotechnical engineering investigation of the digital system.

\section{APPLICATION OF GIS IN GEOTECHNICAL ENGINEERING INVESTIGATION}

The integrated system of geotechnical engineering investigation and design and the geographic information system belong to two different research areas. However, the engineering mechanical properties of geotechnical engineering have the attributes of geographic information. There is an important similarity between them. The integration of geotechnical engineering investigation and design focuses on the spatial information all based on the design, and the design results to make analysis, evaluation and decision-making. It can not be separated from the full support of the spatial information. And the geographic information system focuses on the collection, management and analysis of various spatial informations [10].
Applied geographic information system technology, to geotechnical engineering survey design, use GIS's powerful data acquisition, management capabilities and spatial query, spatial analysis capabilities, to obtained a large amount of information from soil engineering survey, design, construction, and analysis of the diversity formation. To provide comprehensive information support for analysis, evaluation and making decision of the design scheme can. It will provide an effective way for the exploration and design of geotechnical engineering. As depicted in Figure 3

\section{CONCLUSION}

The integration of geotechnical engineering investigation and design is imperative. Based on the integration of geotechnical investigation and design of GIS, link the GIS to geotechnical engineering investigation and design, and the CAD type of work closely. To form an integrated production system, it will improve the production efficiency, generate huge economic benefits, improve the competitiveness of enterprises, and promote the development of geotechnical engineering investigation and design

Figures and Tables

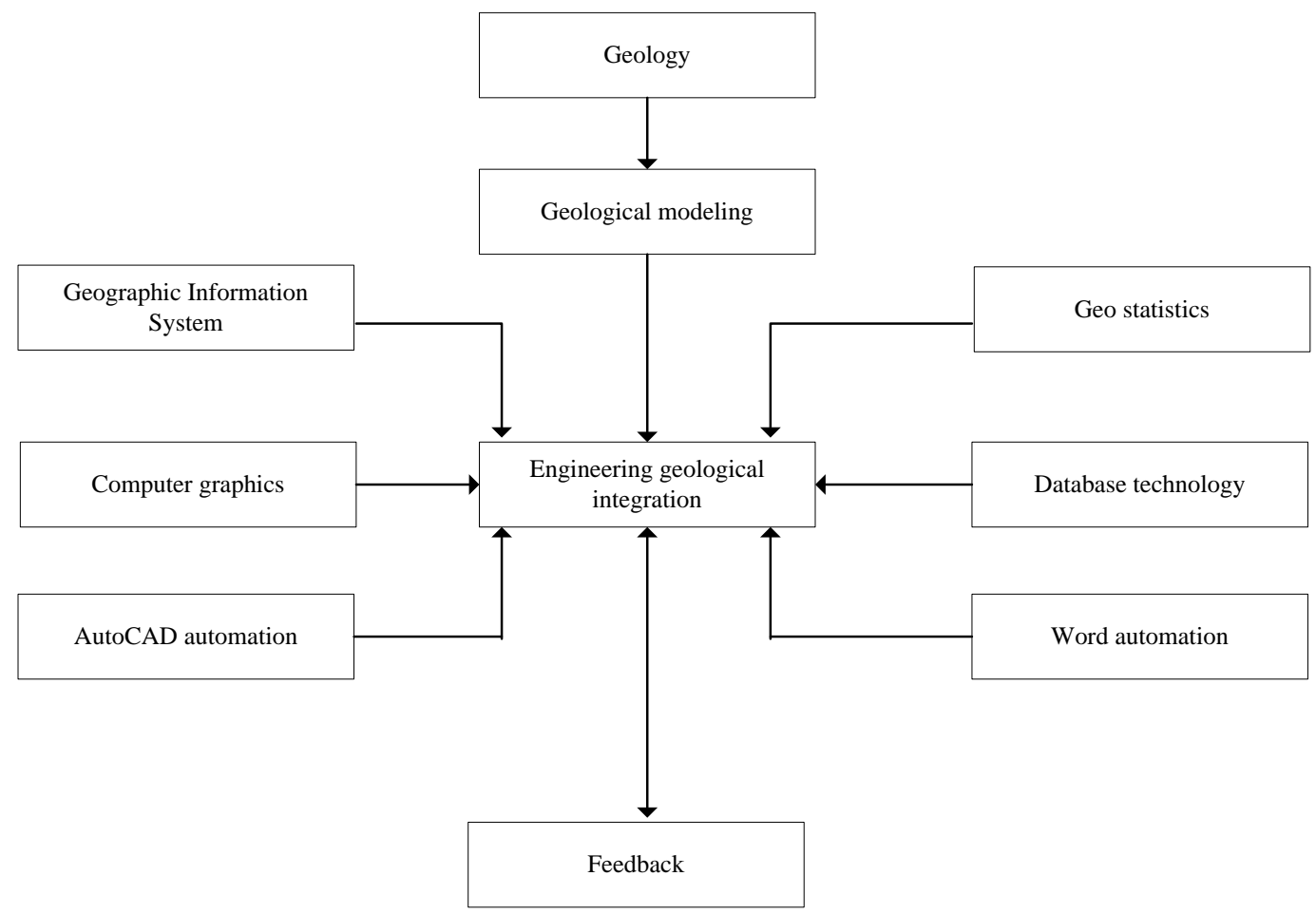

Figure 1. Integrated System of Geotechnical Investigation Engineering 


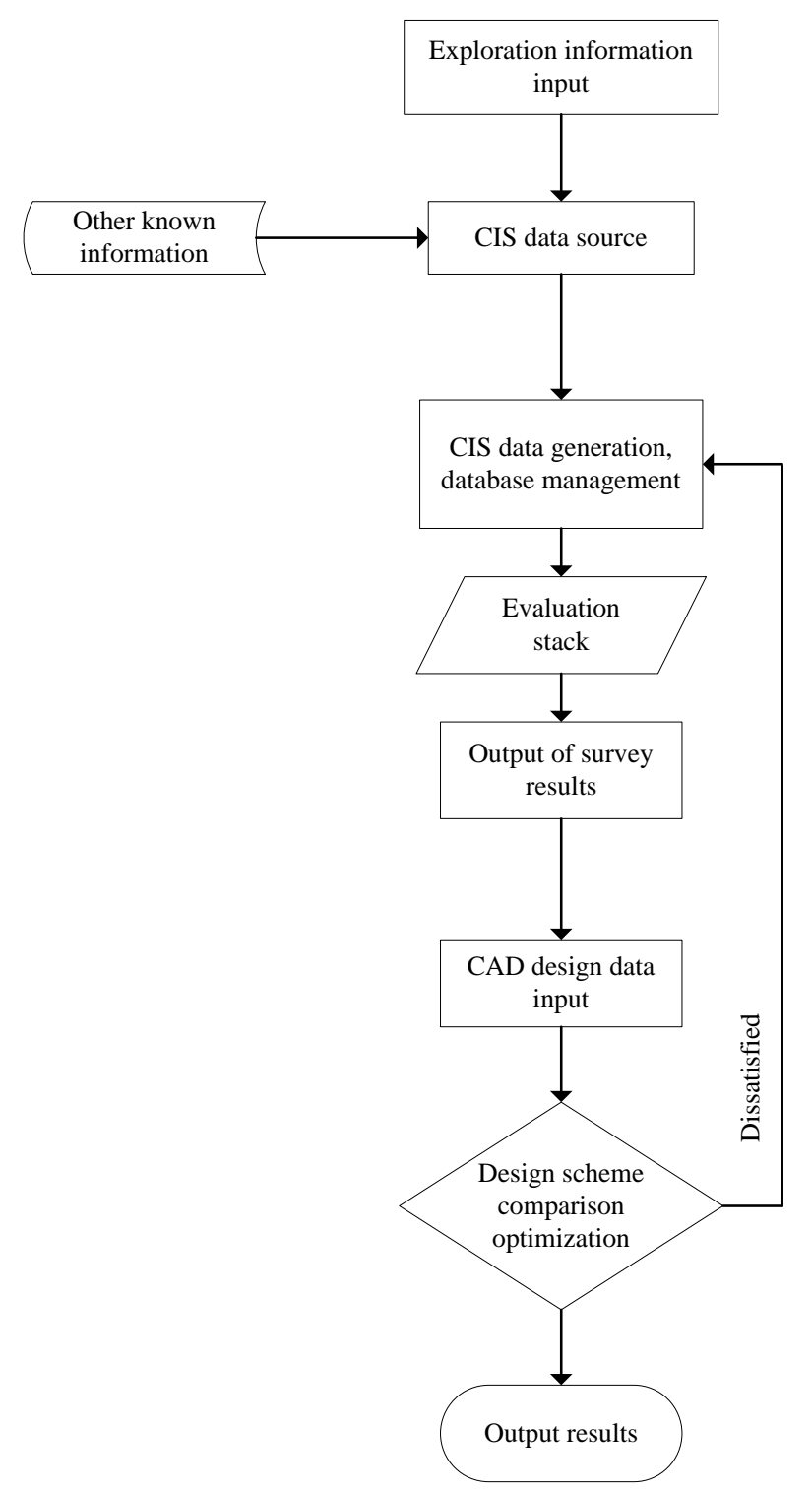

Figure 2. The Sketch of GIS-aided the Integrative of Survey and Design

$1 \quad$ Load and reference topographic basemap (raster)

2 Create a database consisting of faults of different sizes and geometries (linear objects), blocks of different sizes (polygons), and drainage network (linear and polygon layers)

3 Map faults laid over raster basemap according to field data

4 Populate attribute table of linear layers with fault names, lengths, geometries (normal, reverse, or uncertain), dips, and ranks, and with river names

5 Group faults into five ranks on the basis of length (Symbology tab in Layer properties window)

6 Choose color scale and thickness for faults of different ranks (Symbology tab in Layer properties window)

7 Lay out fault map, create legend and export map in any raster format

Figure 3. Workflow chart for 2D modeling of faults (ArcGIS) 


\section{REFERENCES}

[1] Baranov, Yu D., Busygin, B.S., Nikulin, S.L., 2004. 3D reservoir modeling for well placement. Gornyi InformacionnoAnaliticheskii Byulleten 3, 197e201.

[2] Bilibin, S.I., Dyakonova, T.F., Isakova, T.G., Istomin, S.B., Yukanova, E.A., 2007. Threedimensional geological modeling as a critical step in reservoir studies. Nedropolzovanie XXI Vek $4,38 \mathrm{e} 42$

[3] Breunig, M., Cremers, A.B., Götze, H.-J., Schmidt, S Seidemann, R., Shumilov, S., Siehl, A.,1999. First steps towards an interoperable 3D GIS e an example from southern ower Saxony, Germany. Physics and Chemistry of the Earth, Part A 24 (3), 179e190.

[4] Breunig, M., Cremers, A.B., Götze, H.-J., Schmidt, S., Seidemann, R., Shumilov, S.,Siehl, A., 2000. Geological mapping based on 3D models using an interoperableGIS. Geoinformation-systems. Journal for Spatial Information and DecisionMaking 13, 12e18.

[5] Büttner, S.H., Sherlock, S., Fryer, L., Lodge, J., Diale, T., Kazondunge, R., Macey, P.,2013. Controls of host rock mineralogy and $\mathrm{H} 2 \mathrm{O}$ content on the nature of pseudotachylyte melts: evidence from Pan-African faulting in the foreland of the Gariep Belt, South Africa. Tectonophysics 608, 552e575.
[6] Carlos, C.U., Francisco, H.R., Francisco, C.C., Rubson, P., Maria, O.L., 2014. Quaternaryfault control on the coastal sedimentation and morphology of the San Francisco coastal plain, Brazil. Tectonophysics 633, 98e114.

[7] Cassard, D., Billa, M., Lips, A.L.W., et al., 2004. An expertguided data-drivenapproach and scale-related data models for multicriterion processing with GIS andes. In: GIS in Geology. International Conference, Moscow, 15e19 November, 2004 Vernadsky SGM RAS, Moscow, pp. 27e31.

[8] Extended Abstracts.Cheremisina, E.N., Nikitin, A.A., 2006. Geoinformation systems for nature management Geoinformatika 3, 5e20.

[9] Gardoll, S., Groves, D., Knox-Robinson, C., et al., 2000. Developing the tools for geologicalshape analysis, with regional- to local-scale examples from the Kargoorlie Terrane of Western Australia. Australian Journal of Earth Sciences 5, 943e953.

[10] Butler, R.W.H., Shipton, Z.K., Sibson, R.H. (Eds.), Faulting, Fracturing and Igneous Intrusion in the Earth's Crust. Geological Society, London. Special Publication367, pp. 1e6. 